\title{
Delirium epidemiology in critical care (DECCA): an international study
}

\author{
Jorge I Salluh" ${ }^{*}$, Márcio Soares ${ }^{1}$, José M Teles ${ }^{2}$, Daniel Ceraso ${ }^{3}$, Nestor Raimondi ${ }^{3}$, Victor S Nava ${ }^{4}$, Patrícia Blasquez ${ }^{1}$, \\ Sebastian Ugarte ${ }^{5}$, Carlos Ibanez-Guzman ${ }^{6}$, José V Centeno ${ }^{7}$, Manuel Laca ${ }^{8}$, Gustavo Grecco ${ }^{9}$, Edgar Jimenez ${ }^{10}$, \\ Susana Árias-Rivera ${ }^{11}$, Carmelo Duenas ${ }^{12}$, Marcelo G Rocha ${ }^{13}$, \\ The DECCA (Delirium Epidemiology in Critical Care) Study Group
}

\begin{abstract}
Introduction: Delirium is a frequent source of morbidity in intensive care units (ICUs). Most data on its epidemiology is from single-center studies. Our aim was to conduct a multicenter study to evaluate the epidemiology of delirium in the ICU.
\end{abstract}

Methods: A 1-day point-prevalence study was undertaken in 104 ICUs from 11 countries in South and North America and Spain.

Results: In total, 975 patients were screened, and 497 fulfilled inclusion criteria and were enrolled (median age, 62 years; $52.5 \%$ men; $16.7 \%$ and $19.9 \%$ for ICU and hospital mortality); $64 \%$ were admitted to the ICU because of medical causes, and sepsis was the main diagnosis ( $n=76 ; 15.3 \%)$. In total, 265 patients were sedated with the Richmond agitation and sedation scale (RASS) deeper than -3, and only 232 (46.6\%) patients could be evaluated with the confusion-assessment method for the ICU. The prevalence of delirium was 32.3\%. Compared with patients without delirium, those with the diagnosis of delirium had a greater severity of illness at admission, demonstrated by higher sequential organ-failure assessment (SOFA $(P=0.004)$ ) and simplified acute physiology score 3 (SAPS3) scores $(P<0.0001)$. Delirium was associated with increased ICU (20\% versus 5.7\%; $P=0.002)$ and hospital mortality (24 versus 8.3\%; $P=0.0017$ ), and longer ICU $(P<0.0001)$ and hospital length of stay (LOS) (22 (11 to 40$)$ versus 7 (4 to 18 ) days; $P<0.0001)$. Previous use of midazolam $(P=0.009)$ was more frequent in patients with delirium. On multivariate analysis, delirium was independently associated with increased ICU mortality (OR = 3.14 (1.26 to 7.86); $\mathrm{Cl}, 95 \%)$ and hospital mortality (OR $=2.5$ (1.1 to 5.7$)$; $\mathrm{Cl}, 95 \%)$.

Conclusions: In this 1-day international study, delirium was frequent and associated with increased mortality and ICU LOS. The main modifiable risk factors associated with the diagnosis of delirium were the use of invasive devices and sedatives (midazolam).

\section{Introduction}

Delirium is a common cause of acute brain dysfunction in patients admitted to the intensive care unit (ICU) $[1,2]$. To date, several studies have demonstrated that delirium is associated with increased mortality as well as increased hospital length of stay (LOS) and costs [2-4]. In addition, when high-risk populations are considered, such as the elderly and mechanically ventilated, delirium

\footnotetext{
* Correspondence: jorgesalluh@yahoo.com.br

${ }^{1}$ Intensive Care Unit and Postgraduate Program, Instituto Nacional de Câncer, $10^{\circ}$ Andar; Praça Cruz Vermelha, 23; Rio de Janeiro-RJ; CEP: 20230130, Brazil

Full list of author information is available at the end of the article
}

may occur in up to $80 \%$ of ICU patients [5]. The impact of delirium on relevant clinical outcomes is not restricted to the hospital setting, as delirium is also an independent predictor of 6-month mortality and longterm cognitive impairment $[5,6]$. However, most epidemiologic data derive from studies performed in one or a few centers in tertiary hospitals and academic centers where delirium awareness and adherence to best practice is probably increased [7]. Recent surveys involving large numbers of ICU healthcare professionals have demonstrated that despite the increasing knowledge of the pathophysiology, risk factors, and outcomes
C Biomed Central 
associated with delirium, it is still underdiagnosed, and modifiable risk factors related to its occurrence are frequently neglected $[8,9]$. However, these surveys were questionnaires that evaluated the perceptions and not the current practice of these professionals $[8,9]$. Therefore, it is important to describe and understand delirium epidemiology in a wide array of ICUs with different practice patterns. The availability of epidemiologic data from a large number of ICUs may help to design future observational and interventional studies. The aim of the present study was to evaluate the epidemiology of delirium in a large number of ICUs in South and North America and Spain.

\section{Materials and methods}

\section{Design and setting}

This 1-day observational study was performed on November 27, 2009, at 08:00 AM, local time, in 104 ICUs in Argentina, Bolivia, Brazil, Chile, Colombia, Ecuador, Mexico, Peru, Spain, the United States of America, and Uruguay. Pediatric ICUs, postoperative recovery areas, and units providing exclusive coronary care were not included. The institutional review boards approved the study design and waived the need for informed consent. The current study did not interfere with patient-management decisions.

\section{Selection of participants, data collection, and definitions}

ICUs were recruited by using the mailing database from the study coordinator and the Federacion Panamericana e Iberica de sociedades de Medicina Critica y Terapia Intensiva (FPIMCTI). Each investigator and research coordinator was provided access to a website where a comprehensive manual describing data-collection requirements and variable definitions was available. A training manual for the Richmond Agitation and Sedation Scale (RASS) and Confusion Assessment Method for the ICU (CAM-ICU) in Portuguese, Spanish, and English, as well as videos demonstrating the application of the CAM-ICU, were available online for the investigators. A central office was accessible through telephone and email contact to answer questions regarding data collection on the study day and throughout the followup period. All data entry was performed online in a web-based electronic case report form (e-CRF). Data were checked by study coordinators to identify omissions, and inconsistent data were corrected whenever possible. ICU and hospital demographic information collected included the number of ICU beds, number of patients in the ICU at the moment of study, and number of patients meeting inclusion criteria. Patients were excluded from the study if they had a Glasgow coma scale $<14$ from a primary neurologic diagnosis at ICU admission or before the study day on the same hospital admission or both. Legal blindness and deafness and the inability to speak the language of the country where the ICU was located and moribund patients (expected to die in less than 24 hours) were also exclusion criteria. All patients 18 years or older, with more than 24 hours of ICU stay were included regardless of the sedation status. The following information was collected in each patient meeting inclusion criteria on the day of the study: Gender, date of ICU and hospital admission, SAPS3 [10] and SOFA scores [11] at ICU admission, diagnosis, description of previous and current use of sedatives, and the use of antipsychotic agents during the ICU stay. The category of admission (surgical elective versus emergency versus medical) was noted. Sepsis was stratified according to the American College of Chest Physicians/ Society of Critical Care Medicine Consensus Conference criteria [12], and acute lung injury (ALI) and acute respiratory distress syndrome (ARDS) were defined according to the American-European Consensus Conference criteria [13]. The presence of invasive procedures/ monitoring and organ support was recorded. Level of arousal was measured by using the RASS score [14], which rates a patient's level of agitation/sedation on a 10 -point scale ranging from -5 (unarousable, not responsive to voice or physical stimulation) to +4 (combative). Delirium was diagnosed with the CAM-ICU [2]. The CAM-ICU was developed for use in critically ill, intubated patients, and details can be found at the icudelirium website. The CAM-ICU is a validated deliriumdetection tool with high sensitivity and specificity and high interrater reliability $[1,2,5,15]$. The CAM-ICU assesses four features of delirium: (1) acute onset or fluctuating course, (2) inattention, (3) disorganized thinking, and (4) altered level of consciousness. To be considered CAM-ICU positive, the subject must display features 1 and 2, and either 3 or 4. Vital status (alive/ dead) at ICU discharge and study day 30 was registered.

\section{Data presentation and statistical analysis}

Standard descriptive statistics were used. Continuous variables were reported as median (25\% to $75 \%$ interquartile range (IQR)). Univariate analysis was used to identify factors associated with hospital mortality. Twotailed $P$ values $<0.05$ were considered statistically significant. Univariate and multivariate logistic regression were used to identify factors associated with hospital mortality. Variables yielding $P$ values $<0.2$ by univariate analysis were entered into a forward multivariate logistic regression analysis. Multivariate analysis results were summarized by estimating odds ratios (ORs) and respective $95 \%$ confidence intervals (CIs). Possible interactions were tested. The area under the receiver-operating characteristic curve was used to assess the models' discrimination. The SPSS 13.0 software package (Chicago, IL) 


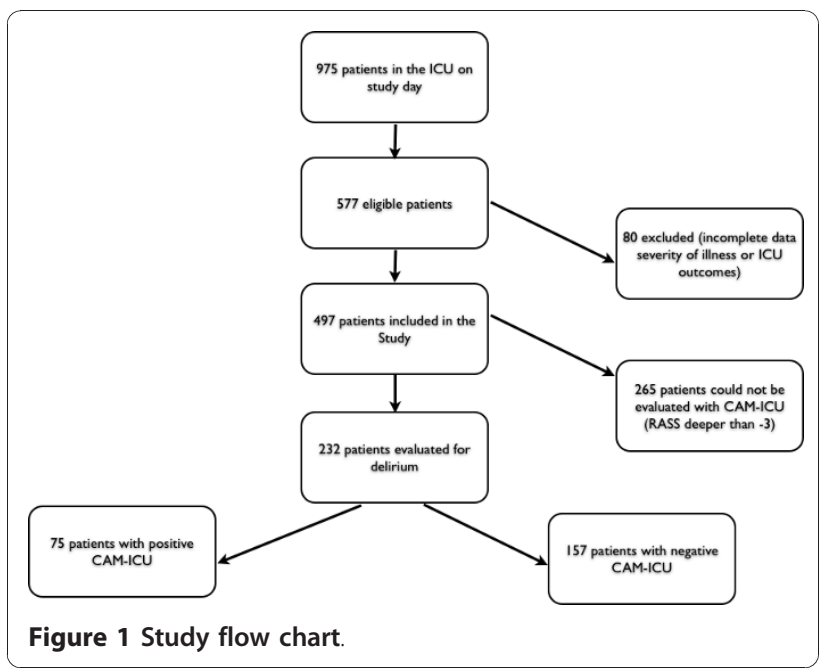

and Prism 3.0 (Graphpad, La Jolla, CA) were used for statistical analysis.

\section{Results}

\section{Characteristics of the study population}

After the initial screening of 975, 497 patients that fulfilled entry criteria were enrolled in the study
(Figure 1). Each institution of the DECCA database with its respective contributing proportion of patients is provided in Additional file 1. The main characteristics of the study population are depicted in Table 1. Overall, ICU and hospital mortality were $16.7 \%$ and $19.9 \%$, respectively. Sixty-four percent were admitted to the ICU because of a medical condition, whereas elective and emergency surgery represented $21.5 \%$ and $14.1 \%$ of cases, respectively. At ICU admission, sepsis was the most frequent diagnosis $(n=76 ; 15.3 \%)$. Mechanical ventilation and vasopressors were used in $38.4 \%$ and $20.7 \%$ of the patients, respectively. Regarding chronic health status, 133 (26.7\%) patients had a previous medical condition and required assistance.

Among eligible patients, on the study day, 140 (20.8\%) patients were receiving continuous infusion or regular administration of sedatives, and in $57(40.7 \%)$ of the patients, interruption of sedation was performed as part of routine ICU care in these units. Considering only those using sedatives on the study day, the level of arousal was RASS $>1$ in $10 \%(n=14)$, RASS -1 to 1 in $35 \%$ $(n=49)$, and RASS $\leq 1$ in $55 \%(n=77)$. For these patients, sedation was considered by the assisting physician to be within the previously established target in 106 (75.7\%) patients.

Table 1 Demographic and clinical variables of patients according to delirium status

\begin{tabular}{|c|c|c|c|c|}
\hline \multirow[t]{2}{*}{ Variables } & \multirow[t]{2}{*}{ All patients $(n=497)$} & \multicolumn{2}{|c|}{ Delirium status $^{a}$} & \multirow[t]{2}{*}{$P$ value } \\
\hline & & Delirium $(n=75)$ & No delirium $(n=157$ ) & \\
\hline Age (years) & $62(47-74)$ & $64(50-77)$ & $61(46-74)$ & 0.2 \\
\hline Male gender, $n(\%)$ & $261(52.5 \%)$ & $41(54.6 \%)$ & $79(50.3 \%)$ & 0.57 \\
\hline SAPS3 score (points) & $49(40-61)$ & $57(48-64)$ & $46(34-56)$ & $<0.0001$ \\
\hline Charlson comorbidity index (points) & $1(0-3)$ & $1(0-3)$ & $1(0-3)$ & 0.89 \\
\hline SOFA score (points) & $4(1-6)$ & $4(3-7)$ & $3(1-5)$ & 0.004 \\
\hline Invasive mechanical ventilation, n (\%) & $191(38.4 \%)$ & $42(56 \%)$ & $36(23 \%)$ & $<0.0001$ \\
\hline Use of vasopressors, $n(\%)$ & $103(20.7 \%)$ & $22(29.3 \%)$ & $21(13.4 \%)$ & 0.007 \\
\hline Renal replacement therapy, $n$ (\%) & $52(10.4 \%)$ & $9(12 \%)$ & $17(10.8 \%)$ & 0.82 \\
\hline \multicolumn{5}{|l|}{ Main reasons for ICU admission } \\
\hline Sepsis, $n$ (\%) & $76(15.3 \%)$ & 19 (25.3\%) & $17(10.8 \%)$ & 0.006 \\
\hline Cardiovascular, n (\%) & $75(15.3 \%)$ & $10(13.3 \%)$ & $30(18.6 \%)$ & 0.35 \\
\hline Respiratory failure, $n$ (\%) & $70(11.7 \%)$ & $9(12 \%)$ & $24(15.3 \%)$ & 0.55 \\
\hline Neurologic, $n(\%)$ & $24(4.8 \%)$ & $12(9.1 \%)$ & $5(3.1 \%)$ & 0.004 \\
\hline \multicolumn{5}{|l|}{ Invasive devices } \\
\hline Central venous catheter & $317(63.8 \%)$ & $64(85.3 \%)$ & $85(54.1 \%)$ & $<0.0001$ \\
\hline Arterial catheter & $158(31.8 \%)$ & $29(38.6 \%)$ & $32(20.4 \%)$ & 0.004 \\
\hline Urinary catheter & $324(65.1 \%)$ & $62(82.6 \%)$ & $89(56.7 \%)$ & 0.0001 \\
\hline ICU LOS (days) & $10(4-24)$ & $22(11-40)$ & $7(4-18)$ & $<0.0001$ \\
\hline ICU mortality, n (\%) & $83(16.7 \%)$ & $15(20 \%)$ & $9(5.7 \%)$ & 0.002 \\
\hline Hospital mortality, $n(\%)^{b}$ & $88(19.9 \%)$ & $18(24 \%)$ & $13(8.3)$ & 0.0017 \\
\hline
\end{tabular}

The $P$ values are for comparisons among patients with and without the diagnosis of delirium. ${ }^{a}$ Only those evaluated for delirium were considered. ${ }^{b}$ Only those with death or discharge at day 30 were considered $(n=711)$. SAPS3, Simplified Acute Physiology Score 3; SOFA, Sequential Organ Failure Assessment; ICU, intensive care unit; LOS, length of stay. Results are expressed as median (25\% to $75 \%$ interquartile range) and number (\%). 


\section{Diagnosis of delirium: associated characteristics and outcomes}

After excluding patients deeply sedated and unarousable with RASS deeper than -3, delirium was evaluated with the CAM-ICU in 232 patients (46.7\% of the entire eligible patient population). Overall, delirium was diagnosed with the CAM-ICU in 75 (32.2\%) of the included arousable patients. Detailed comparisons between patients with and without a diagnosis of delirium are depicted in Table 1 . Patients with delirium were more severely ill, as reflected by higher SAPS3 and SOFA scores $(P<0.0001$ and $P=0.004$, respectively). In addition, patients with delirium had more frequent use of invasive mechanical ventilation, vasopressors as well as invasive devices, such as central venous and arterial catheters (Table 1). Additionally, patients with delirium used haloperidol more frequently $(21.3 \%$ versus $3.8 \% ; P<0.0001)$ as compared with those without delirium. The overall use of atypical antipsychotics was low and similar in the two groups (5.3\% versus $4.4 \% ; P=0.75$ ). Regarding the use of sedatives during the ICU stay, only the use of midazolam was associated with the diagnosis of delirium (42.6\% in patients with delirium versus $24.8 \%$ in those without the diagnosis of delirium; $P=0.009$ ). Additional data on the use of sedatives is provided in Table 2.

Variables selected in the univariate analysis were entered into the multivariate analysis. As expected, potential collinearity between the SOFA and SAPS3 scores (Pearson's correlation coefficient, $r=0.43$ ) was observed. Therefore, two models were fitted containing either the SAPS3 or the SOFA score. In addition to the SAPS3 and SOFA scores, delirium was selected in the final models and associated with ICU mortality (Table 3). On multivariate analysis, delirium was independently associated with increased ICU mortality $(\mathrm{OR}=3.14$ (1.26 to 7.86); CI, 95\%) and hospital mortality (OR $=2.5$ (1.1 to 5.7$)$; CI, 95\%).

When patients with RASS deeper than -3 were analyzed, we observed that they had increased ICU mortality $(P<0.0001)$ and severity of illness (SAPS3, 49 (40 to 61] versus 46 (34 to 56$) ; P=0.01$ ) but a similar age

Table 2 Use of sedatives in patients with and without a diagnostic of delirium

\begin{tabular}{llll}
\hline & $\begin{array}{l}\text { Delirium } \\
(\boldsymbol{n}=\mathbf{7 5})\end{array}$ & $\begin{array}{l}\text { No delirium } \\
(\boldsymbol{n}=\mathbf{1 5 7 )}\end{array}$ & $\boldsymbol{P}$ value \\
\hline Midazolam & $32(42.6 \%)$ & $39(24.8 \%)$ & 0.009 \\
Other benzodiazepines & $11(14.68 \%)$ & $20(12.7 \%)$ & 0.68 \\
Fentanyl & $26(34.6 \%)$ & $34(21.6 \%)$ & 0.15 \\
Morphine & $12(16 \%)$ & $21(13.4 \%)$ & 0.41 \\
Propofol & $12(16 \%)$ & $11(7 \%)$ & 0.058 \\
Dexmedetomidine & $12(16 \%)$ & $13(8.3 \%)$ & 0.11 \\
\hline
\end{tabular}

Results are expressed as number and percentage. Only those evaluated by the CAM-ICU were included in the analysis.
Table 3 Multivariate analyses of factors associated with increased ICU mortality

\begin{tabular}{lcll}
\hline Variables & Coefficient & $\begin{array}{l}\text { Odds ratio }(\mathbf{9 5 \%} \% \\
\mathbf{C l})\end{array}$ & $\begin{array}{l}\boldsymbol{P} \\
\text { value }\end{array}$ \\
\hline Model containing the SAPS3 score & & \\
Delirium & 1.147 & $3.15(1.26-7.86)$ & 0.014 \\
SAPS3 Score (points) & 0.03 & $1.03(0.99-1.06)$ & 0.06 \\
Constant & -4.309 & &
\end{tabular}

Model containing the SOFA

score

\begin{tabular}{llll} 
SOFA Score (points) & 0.14 & $1.14(1.01-1.29)$ & 0.023 \\
Delirium & 1.21 & $3.36(1.36-8.29)$ & 0.008 \\
\hline Constant & -3.384 & &
\end{tabular}

Model containing the SAPS3 Score: Area under receiver operating characteristic curve $=0.73(95 \% \mathrm{Cl}, 0.67$ to 0.79$)$. Model containing the SOFA Score: Area under receiver operating characteristic curve $=0.75(95 \% \mathrm{Cl}, 0.69$ to 0.80 ). SAPS3, Simplified Acute Physiology Score 3; SOFA, Sequential Organ Failure Score; $\mathrm{Cl}$, confidence interval.

(62 (46 to 74 ) versus 61 (46 to 74$) ; P=0.8$ ) as compared with patients without a diagnosis of delirium. When compared with those that were arousable and presented a diagnosis of delirium, deeply sedated patients had similar ICU mortality $(P=0.87)$ but a lower severity of illness (SAPS3, 49 (40 to 61) versus 57 (48 to 64$) ; P=0.0005)$ and a comparable age (62 (46 to 74 ] versus 64 (50 to 77 ); $P=0.28$ ).

\section{Discussion}

In this multicenter international study, we observed that, through a single standardized evaluation, delirium was diagnosed in $32 \%$ of the patients. Moreover, our data show that delirium was also associated with longer duration of hospitalization and was an independent predictor of ICU and hospital mortality. Considering the increasing costs associated with the ICU and hospital stay and the fact that delirium is often unrecognized $[8,9,16]$, our findings have an increasing relevance. Additionally, mounting evidence suggests that delirium is associated with the risk of self-extubation, removal of catheters, and failed extubation, adverse events that are associated with worse outcomes [17]. Therefore, data from the present study showing its increased prevalence in academic and nonacademic centers, in private and public hospitals, as well as in different countries provide additional support to the recommendation for the use of a validated delirium-screening tool such as the CAM-ICU as a routine in the ICU $[18,19]$.

The $32 \%$ incidence of delirium in the present study is comparable to that in previous reports from mixed ICU populations [4] but is lower than the incidence of around $80 \%$ observed in studies involving exclusively mechanically ventilated patients [5]. Such a significant difference may be ascribed to patients' characteristics 
(for example, case mix, disease severity, age), the tool used for delirium assessment, and sedation practices. Another aspect that could have influenced the present prevalence is related to the fact that patients in a coma or deeply sedated or both were not considered in the present study as they could not be evaluated with the CAM-ICU. Although coma and delirium are different clinical conditions, both can be classified as acute brain dysfunction [20]. Certainly, patients with delirium are prone to receive sedatives, especially when the hyperactive form is present; this could have led to a higher frequency of coma and oversedation but also to underestimation of the delirium rates in the present study.

Our findings have significant clinical and research implications. First, they confirm the previous findings from single-center studies showing that among medical/ surgical ICU patients, delirium is associated with adverse outcomes, including prolonged ICU hospital stay, and is an independent predictor of increased shortterm mortality [2,5,21]. Among factors associated with delirium in our study, invasive devices and the use of midazolam are to be considered potentially modifiable risk factors. Among sedatives, only midazolam reached statistical significance; however a trend was observed with propofol $(P=0.058)$ another $\gamma$-aminobutyric acid (GABA)-agonist sedative. The lack of association observed with other benzodiazepines may be explained by a type II error, as the study was probably underpowered to detect this association. Therefore, we consider that routine delirium assessment, judicious use of sedatives, and early removal of invasive devices (that is, catheters, drains, tubes) to be incorporated into the plan of care of critically ill adults. These and other strategies intended to decrease the frequency and severity of delirium have been successfully tested in non-ICU hospitalized high-risk patients (that is, restraint reduction, early device removal, frequent mobilization, hearing and visual aids, and efforts to improve patient communication through assistive strategies) [22] and should be implemented in the critical care setting.

Finally, different patterns of practice may play an important role in critical care outcomes [23]. Currently, a paucity of data exists regarding global prevalence and practice regarding delirium. In most published studies evaluating delirium, the enrolled patients are predominantly from North America and Europe, even though delirium in the ICU is a global challenge. In this regard, data from multicenter studies in different regions of the world are important to provide additional information and to allow better design of future clinical trials.

Our study has some shortcomings that must be addressed. First, it is a 1-day point-prevalence study, and potential seasonal selection bias cannot be ruled out. Nonetheless, enrolling a large number of ICUs usually diminishes this aspect. In addition, follow-up was restricted to 30 days; therefore, we were not able to address the impact of delirium on long-term morbidity and mortality of our population of critically ill patients. Even so, the present study provides solid data from a large number of ICUs in 11 countries demonstrating that delirium is not only prevalent but also independently associated with increased ICU LOS, mortality, and hospital mortality.

In a point-prevalence study, one must deem possible that other factors may affect patients' outcomes. One possible factor might be related to significant practice variation in delirium treatment $[8,9,24]$. Delirium is treated in various ways (that is, physical restraint, sedatives, antipsychotics), and such diverse approaches may have effects on the clinical outcomes evaluated in our study. Furthermore, in the present study, delirium was considered a dichotomous variable, a yes/no event. Thus, it is reasonable to consider that our results could have varied if delirium severity and duration were measured [5,25-27]. Regarding the factors associated with delirium in our study, the current design does not allow us to establish a true "cause/effect" relation between delirium and the selected outcomes. However, our multicenter study involving numerous ICUs does provide evidence of the negative effect of delirium on major clinical outcomes in mixed critically ill patients.

\section{Conclusions}

This 1-day point-prevalence international study confirms previous findings from single-center studies showing that delirium occurs frequently and is independently associated with adverse outcomes in general ICU patients. Among clinical characteristics associated with the diagnosis of delirium, the use of invasive devices and midazolam were identified and may be considered potentially modifiable risk factors. The study provides a "real world" picture of delirium in general ICU patients in many different countries, and the data should prove useful in the design of trials of pharmacologic and nonpharmacologic interventions for delirium.

\section{Key messages}

- The application of a single standardized evaluation may diagnose delirium in $32 \%$ of general ICU patients.

- The diagnosis of delirium is associated with worse outcomes including longer ICU and hospital length of stay and is independently associated with shortterm mortality.

- The use of invasive devices and sedatives (midazolam) is associated with the diagnosis of delirium. These should be considered modifiable risk factors in the ICU, prompting the inclusion of a systematic 
evaluation for early device removal and judicious sedation in patients' plan of care.

\section{Additional material}

\section{Additional file 1: A description of each institution of the DECCA} database with its respective contributing proportion of patients.

\section{Abbreviations}

ALI: acute lung injury; ARDS: acute respiratory distress syndrome; CAM-ICU: confusion-assessment method for the ICU; Cl: confidence interval; ICU: intensive care unit; IQR: interquartile range; LOS: length of hospital stay; MV: mechanical ventilation; OR: odds ratio; RASS: Richmond agitation and sedation scale; SAPS3: Simplified Acute Physiology Score 3.

\section{Acknowledgements}

MS receives an individual research grant from CNPq.

We thank the Associação Brasileira de Medicina Intensiva (AMIB) [28] for the logistic support during the investigators' meetings. The study was funded through the Federacion Panamericana e Iberica de sociedades de Medicina Critica y Terapia Intensiva (FPIMCTI). Hospira Inc. (Lake Forest, IL) had no role in the design or conduct of the study; in the collection, analysis, and interpretation of the data; in the preparation, review, or approval of this manuscript; or in the publication strategy of the results of this study. These data are being used exclusively to advance the knowledge of brain dysfunction in critically ill patients.

This study was presented as an Oral Presentation at the $23^{\text {rd }}$ Congress of the European Society of Intensive Care Medicine in Barcelona, Spain, October 9 to $13,2010$.

\section{Author details}

${ }^{1}$ Intensive Care Unit and Postgraduate Program, Instituto Nacional de Câncer, $10^{\circ}$ Andar; Praça Cruz Vermelha, 23; Rio de Janeiro-RJ; CEP: 20230130, Brazil. ${ }^{2}$ Intensive Care Unit, Hospital da Bahia, Av. Prof. Magalhaes Neto, 1541, Pituba. Cep:41830-030, Salvador, Bahia, Brazil. ${ }^{3}$ Intensive Care Unit, Hospital Juan A. Fernandez, Cervino 3356, Buenos Aires (ZIP-1425), Argentina. ${ }^{4}$ Postgraduate Program Critical Care, Morones Prieto 3000 Doctores, 64710 Monterrey, Nuevo León, Mexico. ${ }^{5}$ Intensive Care Unit Hospital del Salvador y Clínica INDISA, Avenida Santa María 1810, Providencia, Zip 7500000, Santiago, Chile. ${ }^{6}$ Intensive Care Unit, Unidad de Terapia Intensiva Hospital Obrero N 1 Av Brasil s/n CP 8908, La Paz, Bolivia. 'Intensive Care Unit, Hospital Luis Vernaza, Ext. 2005 Julián Coronel y Loja, 2560300, Guayaquil, Ecuador. ${ }^{8}$ Intensive Care Unit, Hospital Naval, Avenida Santos Chocano s/n, CP 210001, Lima, Peru. ${ }^{9}$ Intensive Care Unit, Sanatorio Americano, 2466 Isabelino Bosch, CP 11600, Montevideo, Uruguay. ${ }^{10}$ Intensive Care Unit, Orlando Regional Medical Center, 86 W. Underwood, MP 80, Orlando, FL 32806, USA. ${ }^{11}$ Intensive Care Unit, Hospital Universitario de Getafe, Carretera de Toledo Km 12,500, Getafe, 28905, Madrid, Spain. ${ }^{12}$ Intensive Care Unit and Postgraduate Program, Universidad de Cartagena, Nuevo Hospital Bocagrande, Calle 5 kra 6, Cartagena, 57, Colombia. ${ }^{13}$ Intensive Care Unit, Pavilhão Pereira Filho, Santa Casa de Misericórdia de Porto Alegre, Rua Annes Dias 285 CEP-90020, Porto Alegre, Brazil.

\section{Authors' contributions}

JIFS, MS, and MGR contributed to the study conception and design, carried out and participated in data analysis, and drafted the manuscript. All authors worked on patient inclusion and helped to revise the manuscript. All authors read and approved the final manuscript.

\section{Competing interests}

The study was funded by the Federacion Panamericana e Iberica de sociedades de Medicina Critica y Terapia Intensiva (FPIMCTI). JIFS, JMT, and MGR have received honoraria and unrestricted research grants from Hospira, Inc. All other authors report that they have no competing interests.

Received: 5 August 2010 Revised: 21 October 2010 Accepted: 23 November 2010 Published: 23 November 2010

\section{References}

1. Morandi A, Pandharipande P, Trabucchi M, Rozzini R, Mistraletti G, Trompeo AC, Gregoretti C, Gattinoni L, Ranieri MV, Brochard L, Annane D, Putensen C, Guenther U, Fuentes P, Tobar E, Anzueto AR, Esteban A, Skrobik Y, Salluh JI, Soares M, Granja C, Stubhaug A, de Rooij SE, Ely EW: Understanding international differences in terminology for delirium and other types of acute brain dysfunction in critically ill patients. Intensive Care Med 2008, 34:1907-1915.

2. Ely EW, Inouye SK, Bernard GR, Gordon S, Francis J, May L, Truman B, Speroff T, Gautam S, Margolin R, Hart RP, Dittus R: Delirium in mechanically ventilated patients: validity and reliability of the confusion assessment method for the intensive care unit (CAM-ICU). JAMA 2001 286:2703-2710.

3. Devlin JW, Fong JJ, Howard EP, Skrobik Y, McCoy N, Yasuda C, Marshall J: Assessment of delirium in the intensive care unit: nursing practices and perceptions. Am J Crit Care 2008, 17:555-565; quiz 566.

4. Ouimet S, Kavanagh BP, Gottfried SB, Skrobik Y: Incidence, risk factors and consequences of ICU delirium. Intensive Care Med 2007, 33:66-73.

5. Ely EW, Shintani A, Truman B, Speroff T, Gordon SM, Harrell FE Jr, Inouye SK, Bernard GR, Dittus RS: Delirium as a predictor of mortality in mechanically ventilated patients in the intensive care unit. JAMA 2004, 291:1753-1762.

6. Girard TD, Jackson JC, Pandharipande PP, Pun BT, Thompson JL, Shintani AK, Gordon SM, Canonico AE, Dittus RS, Bernard GR, Ely EW: Delirium as a predictor of long-term cognitive impairment in survivors of critical illness. Crit Care Med 2010, 38:1513-1520.

7. Esteban A, Ferguson ND, Meade MO, Frutos-Vivar F, Apezteguia C Brochard L, Raymondos K, Nin N, Hurtado J, Tomicic V, Gonzalez M, Elizalde J, Nightingale P, Abroug F, Pelosi P, Arabi Y, Moreno R, Jibaja M, D'Empaire G, Sandi F, Matamis D, Montanez AM, Anzueto A: Evolution of mechanical ventilation in response to clinical research. Am J Respir Crit Care Med 2008, 177:170-177.

8. Salluh Jl, Dal-Pizzol F, Mello PV, Friedman G, Silva E, Teles JM, Lobo SM, Bozza FA, Soares M: Delirium recognition and sedation practices in critically ill patients: a survey on the attitudes of 1015 Brazilian critical care physicians. J Crit Care 2009, 24:556-562.

9. Patel RP, Gambrell M, Speroff T, Scott TA, Pun BT, Okahashi J, Strength C, Pandharipande P, Girard TD, Burgess H, Dittus RS, Bernard GR, Ely EW: Delirium and sedation in the intensive care unit: survey of behaviors and attitudes of 1384 healthcare professionals. Crit Care Med 2009, 37:825-832.

10. Metnitz PG, Moreno RP, Almeida E, Jordan B, Bauer P, Campos RA, lapichino G, Edbrooke D, Capuzzo M, Le Gall JR: SAPS 3: from evaluation of the patient to evaluation of the intensive care unit; Part 1, Objectives, methods and cohort description. Intensive Care Med 2005, 31:1336-1344.

11. Vincent $J$, Moreno R, Takala J, Willatts S, De Mendonca A, Bruining $H$, Reinhart CK, Suter PM, Thijs LG: The SOFA (Sepsis-related Organ Failure Assessment) score to describe organ dysfunction/failure: on behalf of the Working Group on Sepsis-Related Problems of the European Society of Intensive Care Medicine. Intensive Care Med 1996, 22:707-710.

12. Bone RC, Balk RA, Cerra FB, Dellinger RP, Fein AM, Knaus WA, Schein RM, Sibbald WJ: Definitions for sepsis and organ failure and guidelines for the use of innovative therapies in sepsis: the ACCP/SCCM Consensus Conference Committee: American College of Chest Physicians/Society of Critical Care Medicine. Chest 1992, 101:1644-1655.

13. Bernard GR, Artigas A, Brigham KL, Carlet J, Falke K, Hudson L, Lamy M, Legall JR, Morris A, Spragg R: The American-European Consensus Conference on ARDS: definitions, mechanisms, relevant outcomes, and clinical trial coordination. Am J Respir Crit Care Med 1994, 149:818-824.

14. Riker RR, Picard JT, Fraser GL: Prospective evaluation of the SedationAgitation Scale for adult critically ill patients. Crit Care Med 1999, 27:1325-1329.

15. Pandharipande $P$, Jackson J, Ely EW: Delirium: acute cognitive dysfunction in the critically ill. Curr Opin Crit Care 2005, 11:360-368.

16. Rabinowitz T: Delirium: an important (but often unrecognized) clinical syndrome. Curr Psychiatry Rep 2002, 4:202-208.

17. Garrouste Orgeas M, Timsit JF, Soufir L, Tafflet M, Adrie C, Philippart F, Zahar JR, Clec'h C, Goldran-Toledano D, Jamali S, Dumenil AS, Azoulay E, Carlet J: Impact of adverse events on outcomes in intensive care unit patients. Crit Care Med 2008, 36:2041-2047. 
18. Jacobi J, Fraser GL, Coursin DB, Riker RR, Fontaine D, Wittbrodt ET, Chalfin DB, Masica MF, Bjerke HS, Coplin WM, Crippen DW, Fuchs BD, Kelleher RM, Marik PE, Nasraway SA Jr, Murray MJ, Peruzzi WT, Lumb PD: Clinical practice guidelines for the sustained use of sedatives and analgesics in the critically ill adult. Crit Care Med 2002, 30:119-141.

19. Pandharipande P, Banerjee A, McGrane S, Ely EW: Liberation and animation for ventilated ICU patients: the ABCDE bundle for the backend of critical care. Crit Care 2010, 14:157.

20. Kress JP: The complex interplay between delirium, sepsis and sedation. Crit Care 2010, 14:164.

21. Girard TD, Pandharipande PP, Ely EW: Delirium in the intensive care unit. Crit Care 2008, 12(suppl 3):S3.

22. Inouye SK, Bogardus ST Jr, Charpentier PA, Leo-Summers L, Acampora D, Holford TR, Cooney LM Jr: A multicomponent intervention to prevent delirium in hospitalized older patients. N Engl J Med 1999, 340:669-676.

23. Beale R, Reinhart K, Brunkhorst FM, Dobb G, Levy M, Martin G, Martin C, Ramsey G, Silva E, Vallet B, Vincent JL, Janes JM, Sarwat S, Williams MD: Promoting Global Research Excellence in Severe Sepsis (PROGRESS): lessons from an international sepsis registry. Infection 2009, 37:222-232.

24. Mac Sweeney R, Barber V, Page V, Ely EW, Perkins GD, Young JD, McAuley DF: A national survey of the management of delirium in UK intensive care units. QJM 2010, 103:243-251.

25. Pisani MA, Kong SY, Kasl SV, Murphy TE, Araujo KL, Van Ness PH: Days of delirium are associated with 1-year mortality in an older intensive care unit population. Am J Respir Crit Care Med 2009, 180:1092-1097.

26. Pisani MA, Murphy TE, Araujo KL, Slattum P, Van Ness PH, Inouye SK: Benzodiazepine and opioid use and the duration of intensive care unit delirium in an older population. Crit Care Med 2009, 37:177-183.

27. Pisani MA, Murphy TE, Araujo KL, Van Ness PH: Factors associated with persistent delirium after intensive care unit admission in an older medical patient population. J Crit Care 2010, 25:540.e1-540.e7.

28. Associação Brasileira de Medicina Intensiva. [http://www.amib.com.br].

\section{doi:10.1186/cc9333}

Cite this article as: Salluh et al.: Delirium epidemiology in critical care (DECCA): an international study. Critical Care 2010 14:R210.

\section{Submit your next manuscript to BioMed Central and take full advantage of:}

- Convenient online submission

- Thorough peer review

- No space constraints or color figure charges

- Immediate publication on acceptance

- Inclusion in PubMed, CAS, Scopus and Google Scholar

- Research which is freely available for redistribution 